\title{
CONFIGURACIÓN PATRIMONIAL DEL MONASTERIO DE MONJAS DOMINICAS DE SAN JUAN DE QUEJANA, PATRONAZGO DEL LINAJE DE AYALA (1378-1524)*
}

\author{
POR \\ Agurtzane PAZ MORO ${ }^{1}$ \\ Departamento de Historia Medieval, Moderna y de América, \\ Facultad de Letras, Universidad del País Vasco
}

\begin{abstract}
RESUMEN
El proceso de configuración patrimonial del monasterio de San Juan de Quejana es un reflejo del estrecho vínculo creado entre éste y el linaje de Ayala, su fundador y patrono. Las generosas donaciones practicadas garantizaron la subsistencia de la comunidad durante gran parte del periodo bajomedieval. No obstante, las relaciones entre ambos se deterioraron desde finales del siglo xv y las mujeres tomaron el relevo dotacional. Paralelamente, se manifestó una crisis económica interna que requirió la puesta en producción de ciertas propiedades hasta entonces en desuso.
\end{abstract}

PALABRAS CLAVE: patrimonio monástico; patronato; predicadores; linaje de Ayala; San Juan de Quejana (Álava); siglos XIV-XVI.

\section{THE CONFIGURATION OF THE ESTATE OF THE DOMINICAN NUNS OF SAN JUAN DE QUEJANA, PATRONAGE OF THE AYALA LINEAGE (1378-1524)}

\begin{abstract}
The way in which the estate of the convent of San Juan de Quejana came together is a reflection of the close links between the convent and the Ayala lineage, its founder and patron. The family's generous donations guaranteed the survival of the community throughout the whole late medieval period. Nonetheless, relations between the two became strained towards the end of the fifteenth-century, with the Ladies of Ayala assuming the role of principal endowers. Simultaneously the convent experienced internal economic problems which led to previously unexploited properties being put into use.
\end{abstract}

KEY WORDS: monastic estate; patronage; preachers; Ayala lineage; San Juan de Quejana (Álava); $14^{\text {th }}-16^{\text {th }}$ centuries.

Cómo CITAR ESTE ARTículo / CITATION: Paz Moro, A. 2017. «Configuración patrimonial del monasterio de monjas dominicas de San Juan de Quejana, patronazgo del linaje de Ayala (1378-1524)». Hispania Sacra 69, 139: 101-115. doi: 10.3989/hs.2017.007

Recibido/Received 25-09-2014

Aceptado/Accepted $\quad$ 04-05-2016

El solar de Quejana, ubicado en el centro geográfico de Ayala, territorio situado en el extremo noroccidental de la actual provincia de Álava, fue el lugar elegido por el linaje de

* Este artículo se integra en un proyecto de tesis doctoral acerca de la historia medieval del monasterio de San Juan de Quejana, financiado por el Ministerio de Ciencia e Innovación, Subprograma Ayudas FPI-MICINN (BES-2011-046057), en el marco del proyecto de investigación De la Lucha de Bandos a la hidalguía universal: transformaciones sociales, políticas e ideológicas en el País Vasco (siglos XIV y XV), Ministerio de Ciencia e Innovación (HAR 2013-44093-P) y del Grupo (A) de Investigación del Grupo Universitario Vasco Sociedad, poder y cultura, IT-896-16. Ambos están integrados en la Unidad de Formación e Investigación 11/02 Historia, pensamiento y cultura material: Europa y el mundo Atlántico. 6891-906X

1 agurpm@gmail.com / ORCID iD: http://orcid.org/0000-0002-
Ayala para la fundación de un monasterio familiar de dueñas dominicas bajo la advocación de san Juan Bautista. ${ }^{2}$ La transcendencia de este linaje en la corte castellana del periodo bajomedieval, la figura del canciller Ayala y su cultivada formación intelectual, así como la decadencia familiar, personificada en el comunero Pedro de Ayala, conde de Salvatierra, han favorecido la elaboración de numerosos trabajos sobre

2 Abreviaturas y siglas utilizadas: AGS = Archivo General de Simancas; $\mathrm{AMQ}=$ Archivo del Monasterio de Quejana; Apart. = Apartado; $A R C h V=$ Archivo de la Real Chancillería de Valladolid; BNE = Biblioteca Nacional de España; cels. = celemines; Col. = Colección; coord. / coords. = coordinador / coordinadores; dir. = director; ed. = editor; fans. = fanegas; fol. / fols. = folio / folios; Leg. = Legajo; mrs. = maravedís; $\mathrm{ms}$. = manuscritos; $\mathrm{PI}$. = Pleitos; $\mathrm{r}$. = = recto; $\mathrm{RAH}=$ Real Academia de la Historia; RGS = Registro General del Sello; v. ㅇ = vuelto. 
TABLA 1

Donaciones de miembros del linaje de Ayala al monasterio de Quejana

\begin{tabular}{|c|c|c|c|}
\hline Año & Donante & Motivo & Objeto de donación \\
\hline \multirow[t]{12}{*}{1378} & \multirow[t]{12}{*}{ Fray Fernán Pérez de Ayala } & \multirow[t]{12}{*}{ Fundación } & Pie de altar de la iglesia de Quejana -50 fans. anuales- (1) \\
\hline & & & Iglesia de Abecia -50 fans. anuales- (1) \\
\hline & & & Ruedas en Arceniega \\
\hline & & & Ruedas en Ibaizábal -50 fans. anuales- (1) \\
\hline & & & Ruedas de Salmantón -22 fans. anuales- (1) \\
\hline & & & Rueda de Larrinoa \\
\hline & & & Martiniega de Cuartango -1.000 mrs. anuales- \\
\hline & & & Monte de Undio, pasto del ganado vacuno \\
\hline & & & Martiniega de Escalante -1.000 mrs. anuales- \\
\hline & & & Renta de Salinas de Añana -1.500 mrs. anuales- (2) \\
\hline & & & Soldada de 10.000 mrs. \\
\hline & & & Reliquia de Sta. M. ${ }^{\text {a }}$ del Cabello \\
\hline \multirow{2}{*}{1380} & \multirow{3}{*}{ Juan I } & \multirow{9}{*}{ Espirituales } & Renta de Catadiano -500 mrs. anuales- (2) \\
\hline & & & Solar e iglesia de Abornícano -120 fan. anuales- \\
\hline 1390 & & & Diezmos de la mar de Orduña -1.500 mrs. anuales- (3) \\
\hline \multirow{3}{*}{1396} & \multirow{4}{*}{ Enrique III } & & Iglesias de Arrigorriaga y Albizulezaga (2) \\
\hline & & & Alcabalas de ferrerías -2.000 mrs. anuales- (4) \\
\hline & & & Pedido viejo de Arceniega -1.000 mrs. anuales- \\
\hline \multirow[t]{2}{*}{1399} & & & Portazgo de Orduña -3.000 mrs. anuales- (2) \\
\hline & Diego Hurtado de Mendoza & & Martiniega de Domaiquia -400 mrs. anuales- \\
\hline 1404 & Pedro López de Ayala & & Renta de Ameyugo y Valluércanes -100 fans. anuales- \\
\hline 1414 & Fernán Pérez de Ayala & Compensación (5) & Yantar y martiniega de Arciniega -800 mrs. anuales- \\
\hline 1420 & \multirow[t]{2}{*}{ Juan II } & Impagos & Alcabalas del vino de Orduña -3.000 mrs. anuales- \\
\hline 1431 & & \multirow{3}{*}{ Espirituales } & Alcabalas de Orduña -4.000 mrs. anuales- (2) \\
\hline \multirow[t]{2}{*}{1436} & \multirow[t]{2}{*}{ Fernán Pérez de Ayala } & & Exequias -23.000 mrs.- \\
\hline & & & Pedido viejo de Orduña -10.000 mrs. anuales- \\
\hline 1463 & Pedro López de Ayala & Expiatorias & Villa e iglesia de Andollu \\
\hline \multirow[t]{2}{*}{1472} & \multirow[t]{2}{*}{ Constanza de Ayala } & \multirow{8}{*}{ Espirituales } & Alcabalas de Vitoria -5.000 mrs. anuales- (6) \\
\hline & & & Exequias -2.780 mrs.- \\
\hline 1485 & García López de Ayala & & Ruedas de Mendíjur \\
\hline 1496 & María de Ayala & & Testamento -2.306.205 mrs.- \\
\hline \multirow[t]{2}{*}{1509} & \multirow[t]{2}{*}{ Mencía de Ayala } & & Exequias -80.000 mrs. - \\
\hline & & & Alcabalas de Castro -21.000 mrs./20 fans. anuales- (7) \\
\hline \multirow[t]{2}{*}{1516} & \multirow[t]{2}{*}{ María Sarmiento } & & Exequias -30.000 mrs. - \\
\hline & & & Renta para capellanía -13.000 mrs./10 fans. anuales- \\
\hline
\end{tabular}

Notas a la Tabla 1

(1) Datos procedentes del manuscrito ms. 18007, custodiado en la BNE.

(2) Concesiones reales efectuadas por mediación de los señores de Ayala.

(3) Intercambio de la renta de Salinas de Añana por una renta de igual valor situada sobre los diezmos de la mar de Orduña.

(4) Aunque no se especifique es probable que la donación se efectuara tras la renuncia de Pedro López de Ayala, quien habría obtenido esta merced en el año 1377.

(5) Donación realizada en compensación por la usurpación que llevó a cabo el donante con la iglesia de Arrigorriaga.

(6) Manda en la que la donante intercambió el lugar de Tuyo, primer deseo de la testadora, por la renta sobre las alcabalas de la ciudad de Vitoria, manda definitiva.

(7) Renta aportada por su esposo, Antonio de Fonseca, en 1515, para cumplir con la última voluntad de la difunta. 
MAPA 1

Contiene las donaciones que, principalmente, los señores de Ayala efectuaron en favor del monasterio de San Juan de Quejana entre 1374 y 1525

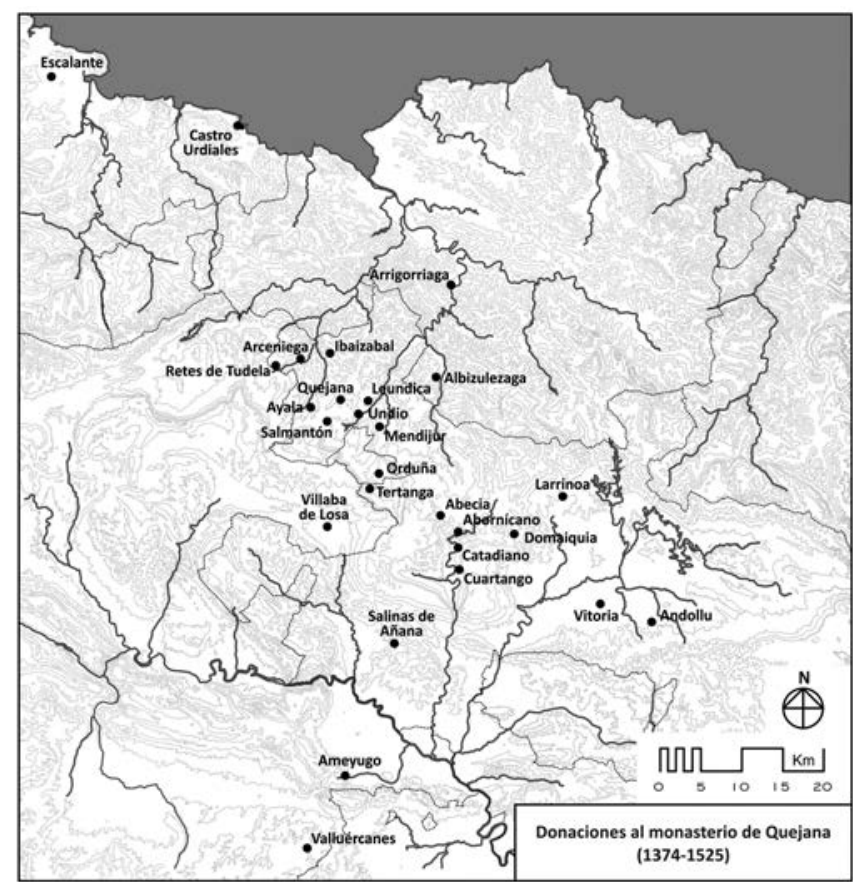

Elaboración: Ismael García.

esta estirpe. ${ }^{3}$ No obstante, su monasterio familiar, en el que instalaron su panteón y al que proporcionaron una gran protección, ha permanecido en un plano secundario.

Los estudios más abundantes sobre el mismo son aquellos dedicados al análisis de sus características formales y artísticas, realizados en los últimos tiempos por autoras como Micaela Portilla, ${ }^{4}$ centrada en exponer las características formales de los edificios que componen el conjunto monumental de Quejana; y de M. Lucía Lahoz ${ }^{5}$ o M.. Luisa Melero Moneo, ${ }^{6}$ con trabajos en los que se describen minuciosamente las particularidades de los proyectos artísticos ejecutados por el linaje en el interior del recinto monástico, enfocados a procurar su descanso eterno. También se han publicado algunos trabajos que pueden ayudarnos a contextualizar la relación entre el monasterio y los Ayala -formación patrimonial, establecimiento del panteón familiar, genealogía del linaje, etc.En este contexto, destacan los trabajos de Ernesto García Fernández ${ }^{7}$ y Arsenio Dacosta, ${ }^{8}$ principalmente. Estos son los hitos bibliográficos más representativos de los últimos años. Partiendo de esta base, y empleando como fuentes principales los documentos custodiados en el archivo monástico, en el Archivo de la Real Chancillería de Valladolid, en el

3 Algunos de los más significativos son: Dacosta 2001 y 2007; García Fernández 2001b y 2007a y Lahoz 2001.

4 Portilla 1983, recoge algunas de las donaciones más significativas efectuadas por el linaje.

5 Lahoz 1993a, 1993b, 1995, 1997, 2001 y 2007.

6 Melero Moneo 2000.

García Fernández 1996 y 2001a. Ambos artículos presentan las donaciones protagonizadas por los Ayala. Mientras que en García Fernández 2007a, también se advierte la transcendencia del panteón familiar instaurado por el linaje.

8 Fundamentalmente en Dacosta 2007.
Archivo Histórico Nacional y en el fondo Salazar y Castro de la Real Academia de la Historia, intentaré definir el proceso de constitución del patrimonio de esta institución eclesiástica y la participación en ese proceso del linaje de Ayala, su principal benefactor. La formación del señorío monástico de Quejana fue el resultado del interés familiar en beneficiar al cenobio, uno de los elementos legitimadores de su acceso al poder y garante de la salvación de sus almas.

Las donaciones de los Ayala se concretaron en la concesión de variadas rentas y bienes raíces que garantizasen el digno sostenimiento de las religiosas y de la estructura conventual (tabla 1, mapa 1).

\section{LA CONSTITUCIÓN INICIAL DEL PATRIMONIO MONÁSTICO (1373-1385)}

El monasterio de San Juan de Quejana fue fundado por Fernán Pérez de Ayala, padre de Pedro López de Ayala, canciller mayor del reino en los años finales del siglo xIV. La llegada de este linaje al valle de Ayala y su acceso al señorío del territorio fue el resultado de un conjunto de complejas circunstancias. El gobierno de la tierra estaba en poder del linaje Salcedo, cuyo último representante, Juan Sánchez de Salcedo, falleció sin descendencia legítima en torno al año 1328. Esta circunstancia determinó la reclamación de estos derechos por parte de varios aspirantes: Sancho García de Murga, sobrino bastardo del difunto, y Sancho Pérez de Ayala, hermano mayor de Fernán Pérez, descendiente de una línea secundaria de los Salcedo, y oriundo de la ciudad de Toledo, donde su linaje se había afincado varias generaciones atrás. El conflicto desembocó en una lucha armada, cuya consecuencia fue la muerte violenta del aspirante de los Murga, y de Sancho Pérez en una emboscada. Por tanto, Fernán Pérez de Ayala, ante la falta de descendencia de su hermano mayor, se convirtió en señor de Ayala. ${ }^{9}$

Estos sucesos provocaron una división entre los linajes menores del territorio y un recelo ante el ascenso de los Ayala al señorío. Así, Fernán Pérez, en el periodo final de su vida, prácticamente coincidiendo con la defunción de su esposa, Elvira Álvarez de Ceballos, inició un proceso legitimador que garantizara los derechos sucesorios de sus descendientes y disipara cualquier controversia sobre su legitimidad. Para ello, utilizó tres expedientes: la elaboración por escrito del Fuero de Ayala, ${ }^{10}$ en 1373, instrumento jurídico que garantizaría el respeto al derecho consuetudinario en el territorio; la redacción de una memoria genealógica, en 1371, que sería continuada por sus descendientes; ${ }^{11}$ y finalmente, la fundación de un monasterio familiar de dueñas predicadoras, adyacente al palacio que construyó, en el que instaló su residencia habitual y el centro de su poder político, donde instauró, además, un panteón familiar, asegurándose así la

\footnotetext{
9 Ibídem: 119-128; García Fernández 2007a: 118-122; García Fernández y Verástegui Cobián 2008: 57-60.

10 Uriarte Lebario 1974.

11 Son los textos: Continuación del Libro del linaje y Andanzas de Fernán Pérez de Ayala, elaborado por su hijo, Pedro López de Ayala, canciller de Castilla; Relación fidelíssima de las sucessiones del linaje de Ayala, posiblemente redactada en época de Pedro López de Ayala, nieto homónimo del Canciller; y La generación y linage que descendió de don Fernán Pérez de Ayala, encargado por García López de Ayala. Dacosta 2007: 17-22 y 135-198.
} 
salvación de su alma mediante los ruegos salvíficos de las religiosas. En este contexto, no ha de extrañar que la base patrimonial del monasterio de Quejana derivase de las sucesivas donaciones realizadas por los Ayala, patronos del cenobio.

\subsection{El proceso fundacional (1373-1379)}

La decisión de proceder a la fundación del monasterio de San Juan de Quejana surgió de un deseo mutuo de Fernán Pérez y su esposa, que se materializó tras el fallecimiento de ésta, en el año 1372:

Sepan quantos esta carta vieren cómmo yo, Fernan Perez de Ayala, frayle de la horden de los Predicadores, porque el tienpo que yo hera casado con doña Elvira de Çavallos, que Dios perdone, aviamos acordado yo y ella de hedificar un monesterio de dueñas predicradoras en el nuestro monesterio de Quexana (...) e señalamos algunas cosas de nuestras heredades para la su mantenençia. E fue voluntad de Dios de la levar d'este mundo, e yo, quiriendo seguir el buen porposyto que yo y ella ovimos, luego que ella finó, di a mis fijos todos los bienes que yo y ella aviamos heredado e ganado (...). E despues que todo esto ove fecho, tomé la horden de los Predicadores e fablé con el prior provinçial e con los buenos de la dicha horden sobre razon de fazer el monesterio de dueñas de la dicha horden segund el porposito primero que yo e la dicha doña Elvira, mi muger, aviamos avido, e ellos ayudaronme a ello en tal manera que, loado sea el nonbre de Dios, el monesterio es fundado y está y prior e dueñas. ${ }^{12}$

Este extracto, incorporado en el texto fundacional, elaborado el 2 de diciembre de 1378, nos muestra los pasos seguidos por el fundador para dar inicio a un proceso que se desarrolló en tres fases. Entre los años 1373 y 1375, Fernán Pérez de Ayala se encargó de asegurar su patrimonio, para lo que procedió a instituir su mayorazgo y a dejar sus asuntos en orden con la elaboración de su testamento. Además, estipuló un primer conjunto de bienes destinados a la dotación del monasterio; en este caso, adjudicados a los capellanes que servirían en el monasterio nombrados por él. Un segundo momento transcurrió entre los años 1375 y 1378, cuando ingresó en el convento de Santo Domingo de Vitoria y, tras contactar con el prior general de la orden de Predicadores, obtuvo la licencia requerida para el establecimiento del cenobio y su adscripción a dicha orden religiosa. En último lugar, a lo largo del año 1378, modificó las condiciones previamente decretadas y dispuso que el cómputo de los bienes legados se emplease en el mantenimiento de las religiosas.

En definitiva, la dotación incial de la primera comunidad instalada en Quejana se integró con bienes de diferente tipología. Por un lado, las rentas: el pie de altar de la iglesia de Quejana, valorado en 50 fanegas de trigo anuales; ${ }^{13}$ los 1.000 maravedís de renta anual sobre la martiniega de Cuartango y otros 1.000 sobre la de Escalante, sacados del

12 AMQ, Apart. A, 30. Las normas de transcripción empleadas son las seguidas por el grupo de investigación del Departamento de Historia Medieval, Moderna y de América de la Universidad del País Vasco en la publicación de su colección de inéditos, v. Munita Loinaz et alii 2014: 271-281.

13 Este rendimiento se encuentra recogido en el manuscrito ms. 18007, custodiado en la BNE. mayorazgo instituido por Fernán Pérez, en diciembre de $1373 ;{ }^{14}$ y una renta de 1.500 maravedís anuales sobre Salinas de Añana, otorgada por el monarca Enrique II en febrero de $1378 .{ }^{15}$ Por otro lado, los derechos de explotación sobre varias ruedas de molino, concretamente las de Larrinoa, Salmantón, Arceniega e Ibaizábal. Esta última estaba en proceso de edificación, por lo que ordenó la entrega de treinta fanegas de trigo anuales al cenobio hasta que se pudiese proceder a su explotación. El fundador, además, otorgó al cenobio el patronazgo sobre la iglesia de Abecia y un sel en Undio, donde pudiese pastar el ganado. ${ }^{16}$

Además de estos bienes, que producían rendimientos anuales permanentes, Fernán Pérez legó un conjunto nada desdeñable de joyas y vestimentas, entre las que se debe destacar la imagen de la Virgen del Cabello. Se trataba de una reliquia familiar, heredada del cardenal Barroso, tío por vía materna de fray Fernán Pérez, que se convirtió en un elemento de gran transcendencia cultual en el monasterio, y favoreció la estrecha conexión entre el linaje y el cenobio, por ser este último el depositario de una reliquia familiar. ${ }^{17} \mathrm{La}$ devoción asociada a esta imagen, y la creencia en sus poderes curativos y en su capacidad para aplacar las inclemencias climáticas vienen descritas en la Reseña histórica del convento de San Juan Bautista de Quejana, elaborada en el año 1756 por el padre Pedro de Lalastra, cura y confesor del cenobio:

Por el dia la tienen en el choro y de noche en el oratorio del dormitorio con su 3v.\%//4r.o lampara peremne. Para esto, al tocar la campana del segundo para ir a la oracion y a prima, las religiosas se juntan en el oratorio todas, jobenes y ancianas, coje la superiora de su altar la sancta imagen con toda veneracion, y cantando el himno todas del Ave Maria Stella la llevan en procesion al choro. La tienen alli, como está dicho, todo el dia, y por la noche, al acabar la maytines, la vuelven con la mesma procesion al dormitorio, cantando el himno de Laudes de la mesma señora, que empieza: "O gloriosa domina", diciendo al mesmo tiempo de acabar de cantar los himnos sus preces, assi en el choro como en el oratorio del dormitorio (...), la llevan tambien en procesion a las enfermas quando estan sacramentadas, y muchas con su visita han recobrado la salud. En qualesquiera necesidades y aogos recurren al punto a ella: en tiempo de serenidad, pidiendo agua quando para los campos hace falta; en tiempo de tempestades, pidiendo serenidad. ${ }^{18}$

En contrapartida a las donaciones concedidas, Fernán Pérez estipuló las obligaciones que debían asumir las monjas recluidas en Quejana, centradas sobre todo en procurar la salvación espiritual de los miembros del linaje -los antepasados enterrados en el lugar, los presentes y los que estaban por

\footnotetext{
14 Fernán Pérez incorporó dos condiciones en su mayorazgo, por las que dividía el territorio entre su primogénito varón, Pedro López de Ayala, heredero del señorío; y su hija Mencía de Ayala, esposa de Beltrán de Guevara, heredera de las propiedades pertenecientes a la Casa de Ceballos, ubicadas en Asturias, Escalante, Trasmiera y Liébana. De cada una de estas condiciones apartó una renta -Cuartango de la de Pedro López y Escalante de la de Mencía- y las entregó a Quejana. Este documento se encuentra transcrito en Contreras y López de Ayala 1972: 79-85 y Ojánguren Iralakoa 1999: 31-32. También está registrado en López Yepes 1974: 108-109.

15 AMQ, Apart. A, 16.

16 Díaz de Durana 2001.

17 Lahoz 2001: 192. Una descripción minuciosa de este artículo podemos encontrarla en Portilla 1961 y 1983: 21-24.

18 AMQ, Apart. 2, Leg. 14, 20.
} 
venir-, y de aquellos que habían favorecido su ascenso social y el incremento de su patrimonio. En este sentido, mención especial recibieron ciertos miembros de estirpe real:

El ánima de la reyna de Aragon, doña Leonor, e las ánimas de sus fijos: el ynfante don Fernando e don Juan, que casé en su casa con doña Elbira, mi muger, e me hizieron mucho vien. Otrosi, les encomiendo el ánima del rey don Pedro que me dio a Quartango. Otrosi, les encomiendo que rueguen por la vida e por la salud del rey don Enrrique, e de la reyna dona Juana, su muger, e del ynfante, su fijo, don Juan, e despues de sus vidas por sus ánimas, porque el rey me fizo e haze mucha merçed.

Éstas fueron las principales posesiones que permitieron la constitución y arranque del monasterio de San Juan de Quejana, una dotación pensada para el digno sostenimiento de un máximo de veinte religiosas. El punto final a este proceso lo proporcionó, en agosto de 1379, el monarca Juan I, cuando integró bajo su amparo y protección el conjunto de las propiedades monásticas, eximiéndolas de toda carga tributaria:

Tomamos en guarda e encomienda el dicho monesterio e las dichas duennas e todos los sus vienes, ansy muebles commo rayzes (...). Otrosy, (...) que los ayan libres e quitos de todo pecho e de todo pidido e de todo trebuto. ${ }^{19}$

Así, asistimos a la fundación de un monasterio dominico en un entorno plenamente rural, particularidad que disiente de los preceptos habituales de la orden, que propugnaban la predicación y optaban por la ubicación de sus instalaciones en ámbitos urbanos ${ }^{20}$. En este contexto, Isabel Beceiro Pita advierte que la elección de las órdenes a las que adscribir estos centros de carácter familiar y sus panteones respondió a «la continuidad en una tradición heredada de los ancestros, o bien de personajes unidos a ellos por lazos de parentesco ficticio o de vasallaje». ${ }^{21}$ Por tanto, la preferencia de Fernán Pérez por la orden dominica fue consecuencia de la confluencia de dos factores. Por un lado, la vinculación del linaje, fundamentalmente de sus predecesores, con don Juan Manuel, promotor de centros dominicos femeninos. ${ }^{22}$ Mientras que por otro, la fundación protagonizada por el cardenal Barroso, su tío, a quien fray Fernán Pérez profesaba una gran admiración, en Santa Práxedes de Aviñón, de características prácticamente idénticas a las incorporadas posteriormente en Quejana. ${ }^{23}$

\footnotetext{
19 Ibídem, Apart. A, 16
}

20 Si bien es cierto que las estrechas relaciones que se establecieron entre la nobleza y los dominicos, fundamentalmente desde fines del XIII y durante los siglos XIV y XV, determinaron una tendencia a implantar estos monasterios en los centros de poder de los linajes que los fundaron y patrocinaron. Por tanto, se aprecia un progresivo abandono de los núcleos urbanos y su instalación en entornos más rurales. García-Serrano Nebras 2014.

21 Beceiro Pita 2014: 320-321.

22 Ibídem, p. 321. Una descripción exhaustiva de los fuertes vínculos que unieron a este individuo con la orden de los Frailes Predicadores podemos encontrarla en García-Serrano Nebras, F. 2014 84-95. Esta vinculación adquiere aún más significado en lo relativo a las casas femeninas, pues su fundación a manos de miembros masculinos de la nobleza castellana fue una excepción, y se limitó a las dos instituidas por don Juan Manuel: San Ildefonso de la Alberca y San Blas de Cifuentes. Pérez Vidal 2013: 148.

23 Lahoz 1995: 288 y García Fernández 2001a: 63.

\subsection{Protectorado de fray Fernán Pérez de Ayala (1379-1385)}

Fray Fernán Pérez, en el documento fundacional del monasterio de Quejana, concedió una generosa dotación inicial al cenobio y a la comunidad recién instalada. A pesar de ello, dedicó los últimos años de su vida a obtener otras mercedes que permitieran una vida más holgada a estas religiosas. Su labor consistió en explotar su faceta como personero del monasterio, mediando con el monarca para la obtención de ciertos privilegios y derechos beneficiosos para el cenobio y su comunidad. El primer ejemplo es la protección bajo la que Juan I integró todas las posesiones monásticas, citada anteriormente. Sin embargo, no es el único, pues el 15 de enero de 1380, el mismo monarca, previa solicitud de fray Fernán Pérez, otorgó una renta de 500 maravedís anuales sobre la aldea de Catadiano, sita en Cuartango. ${ }^{24}$ El 7 de diciembre de ese mismo año, también por su mediación, les concedió el solar, con su iglesia, que el rey poseía en Abornícano, cuyo rendimiento se cifró en 120 fanegas de trigo anuales. ${ }^{25}$

Además de su labor mediadora ante la corte real, fray Fernán Pérez ejecutó ciertas transacciones en nombre del convento y religiosas instaladas en Quejana. Muestra de ello es la compra que efectuó el 22 de septiembre del año 1382, por la que adquirió la mayor parte de las ruedas de "Çamorate" -a excepción de $\frac{1 / 6}{6}$, sitas en Délica:

Otorgamos et connosçemos que vendiemos et vendemos a vos, don Fray Ferrant Perez de Ayala, que estades presente, en voz et en nonbre de [***], priora del <del (repetido) > monesteryo de sennor Sant Johan de Quexana, et de las duennas del dicho monesteryo que agora son et seran de aqui adelante en el dicho monesteryo, et para ellas, yo, la dicha donna Sancha Lopez, muger que fuy del dicho Sancho Lopez de Perea, la terçera parte de las ruedas de Çamorate, que son aqui, en Odelyca, et yo, el dicho Johan Bueno, et yo, la dicha donna Maria Royz, otra terçera parte que nos avemos en las dichas ruedas, et yo, la dicha donna Sancha Lopez, fija de los dichos Sancho Lopez et donna Sancha Lopez, el meyo de la terçera parte que yo he en las dichas ruedas. ${ }^{26}$

\section{EXPANSIÓN PATRIMONIAL ASOCIADA A LAS DONACIONES DE LOS AYALA (1385-1472)}

Este amplio periodo temporal, que abarcó el gobierno de tres señores, se caracterizó por el fuerte protectorado que los Ayala ejercieron sobre el cenobio que fundaron, monopolizando el proceso dotacional del mismo e impidiendo la participación de otros agentes del territorio en su configuración patrimonial, de modo que Quejana se alzó como exponente del poder político, social y económico del linaje en el territorio. Se garantizaban así, prácticamente en exclusividad, los ruegos salvíficos de las religiosas que en él habitaban, dedicados a procurar la salvación espiritual de los miembros del linaje y de aquellos que les beneficiaron en vida. Además, asistimos a un proceso de consolidación del centro monástico como espacio de inhumación, cuya transcendencia se observa en las empresas artísticas que

\footnotetext{
24 AMQ, Apart. A, 18.

25 Ibídem, Apart. A, 4

26 Ibídem, Apart. A, 2 bis.
} 
estos señores protagonizaron en el interior de sus muros, siendo especialmente significativa la del canciller Ayala, quien erigió la capilla de la Virgen del Cabello y ordenó la construcción de su sepulcro y el de su esposa, así como los de sus progenitores.

A la muerte del fundador, fueron sus más inmediatos sucesores los que adoptaron el papel de protectores del cenobio, principalmente durante las tres generaciones siguientes: Pedro López de Ayala, canciller mayor de Castilla, Fernán Pérez de Ayala, su hijo, y Pedro López de Ayala, homónimo y nieto del Canciller. La muerte sin descendencia del último de estos señores y el acceso al señorío de la rama de los Herrera, procedentes de Ampudia, supuso un cambio de tendencia y un desarraigo de estos nuevos Ayala con respecto a Quejana, por lo que la función dotadora fue asumida por las mujeres del linaje.

\subsection{Pedro López de Ayala, canciller de Castilla (1385-1405)}

La incorporación patrimonial durante este periodo no fue obra exclusiva del señor de Ayala, sino que respondió también a la acción individual de otros agentes, entre los que destacaron el monarca y un miembro de la nobleza territorial. Aunque, sin lugar a dudas, fueron las donaciones practicadas por Pedro López de Ayala las que garantizaron el sustento y la ampliación principal de las posesiones de la comunidad. Las donaciones que el canciller Ayala realizó a favor del monasterio de Quejana fueron generosas. Todas ellas se produjeron en los últimos años de su vida, desde finales del siglo XIV, y durante el reinado de Enrique III. Su principal labor a favor del cenobio fue la intervención ante la monarquía. Los servicios que prestó al rey durante toda su vida le granjearon su confianza y pudo solicitar la concesión en capellanía de los monasterios de Arrigorriaga y Albizulezaga, merced otorgada el 3 de septiembre de 1396. ${ }^{27}$

Ambas parroquias se localizan en el vecino señorío de Vizcaya y, a diferencia de las iglesias alavesas, cuyos diezmos se pagaban en especie, sus rendimientos se percibieron en moneda y se fueron revalorizando a medida que avanzaba el siglo XV. Los datos conservados al respecto son sucintos, pero contundentes. El caso de Arrigorriaga, que formó parte del patrimonio monástico hasta el año 1414, resulta ilustrativo. Las noticias existentes, recopiladas por Arsenio Dacosta, indican que mientras formó parte del mayorazgo de la Casa de Ayala, en el año 1383, rendía entre 400 y 450 maravedís. ${ }^{28}$ Sin embargo, en 1414, cuando Fernán Pérez de Ayala, el hijo del Canciller, usurpó esta posesión al monasterio, compensó a las monjas con una renta de 800 maravedís anuales, lo que demuestra la revalorización del rendimiento generado por esta iglesia. En cuanto a la información relativa a Albizulezaga, procede del siglo XVI, del pleito que enfrentó al cenobio con el conde de Salvatierra, y cifra su rendimiento en aproximadamente 10.000 maravedís anuales.

Asimismo, Pedro López de Ayala renunció a sus derechos de percibir los 2.000 maravedís anuales que disfrutaba sobre sus ferrerías de Orozco, Llodio, Ayala y Baracaldo,

27 Ibídem, Apart. A, 8.

28 La revalorización de la renta económica generada por las parroquias integradas en el Señorío de Vizcaya es un hecho constatado, como demuestra Dacosta 1999: 25-34. permitiendo la concesión de una merced enriqueña a favor del cenobio, el 3 de septiembre de $1396 .{ }^{29}$ El origen de esta renta debemos retrotraerlo a la época de fundación del monasterio, concretamente a marzo de 1377, cuando el futuro canciller Ayala, con el objetivo de «labrar e fazer dos ferrerias en su heredat: la una, en Horozco; e la otra, en Barracaldo", solicitó al todavía infante Juan que le eximiese del pago del tributo real que gravaba la producción del hierro, cifrado en un maravedí por cada quintal de hierro que entrase en tierras vizcaínas, aunque limitándolo a un determinado número de quintales:

El fierro de las quales que se y fizier ha de entrar en Vizcaya e me ha de dar a mí, cada anno, de derecho de cada quintal de fierro, un maravedi (...), fasta en quantia que monte el dicho mi derecho dos mill maravedis d'esta moneda usual cada anno. ${ }^{30}$

Apenas dos años y medio después, en enero de 1399, el Canciller cedió los 10.000 maravedís anuales que tenía situados sobre el portazgo de Orduña, renta que había adquirido por su labor como alferez mayor en la orden militar de la Banda, en beneficio de su primogénito, 3.000 de los cuales se otorgaron a las monjas de Quejana:

E mando a los mis contadores mayores que si los dichos diez mill maravedis de la dicha quitaçion del dicho pendon son agora librados, de cada anno, por juro de heredat, al dicho Ferrant Perez, vuestro fijo, que libren los tres mill maravedis d'ellos, de cada anno para sienpre jamás, en el dicho portadgo de Ordunna, a las dichas monjas e convento del dicho monesterio de Sant Juan de Quixana. ${ }^{31}$

En julio del año 1404, de mutuo acuerdo con su esposa, Leonor de Guzmán, donó cien fanegas de trigo anuales sobre las villas de Ameyugo y Valluércanes. ${ }^{32}$ La distribución del pago entre ambas localidades fue la siguiente: sesenta fanegas de trigo anuales procedentes del tributo de Ameyugo y, las cuarenta restantes, del barrio de Yuso de la localidad de Valluércanes.

Además de las contribuciones del señor de Ayala, la monarquía colaboró en el proceso mediante la permuta de una renta y la concesión de una merced. El monarca Juan I, en 1390, tras atender una petición colectiva de la comunidad monástica, intercambió los 1.500 maravedís de renta sobre Salinas de Añana por otra de igual valor sobre los diezmos de la mar de la ciudad de Orduña. ${ }^{33}$ Mientras que en 1396, Enrique III concedió la primera merced real sin mediación previa de un miembro del linaje, materializada en 1.000 maravedís de renta anual sobre el pedido viejo de la villa de Arceniega. ${ }^{34}$

La aportación de Diego Hurtado de Mendoza, almirante mayor de Castilla, es significativa, porque fue la única

29 AMQ, Apart. A, 19

30 Ibídem, Apart. A, 6.

31 Ibídem, Apart. A, 20.

32 Este documento, en teoría depositado en Quejana, cuya única información procede de la transcripción efectuada por Contreras y López de Ayala 1972: 127-128 y de su registro en López Yepes 1974: 159 , se ha perdido, pues no consta en el inventario documental efectuado por Martínez Vázquez 1975, y no queda rastro de él en el archivo monástico.

33 AMQ, Apart. A, 5.

34 Ibídem, Apart. A, 10. 
protagonizada por un miembro ajeno al linaje principal, y que sin embargo estaba emparentado con éste. Fue nieto de Fernán Pérez, fruto del matrimonio de su hija, Aldonza Fernández de Ayala, con Pedro González de Mendoza, señor de Hita y Buitrago. Su contribución, efectuada en 1399, se plasmó en 400 maravedís de renta anual sobre la martiniega de la aldea de Domaiquia, a cambio del cumplimiento de ciertos aniversarios por su alma y la de sus descendientes:

Porque roguedes a Dios por las almas de mi abuelo, don Ferrant Perez, sennor de Ayala, e de mi abuela, donna Elvira de Çavallos, e por las almas de mi padre e mi sennor, don Pero Gonçalez, sennor de Mendoça, e de mi madre e mi sennora, donna Aldonça de Ayala, e por mi vida e mi salud (...) el primer sabado de cada mes fagades dezir una misa cantada de Santa Maria en el altar mayor de la capilla que dizen de Santa Maria del Cabello, e despues de mis dias que sea anibersario. ${ }^{35}$

\subsection{Fernán Pérez de Ayala (1405-1436)}

A la muerte del canciller Ayala, su primogénito, Fernán Pérez de Ayala, homónimo de su abuelo, asumió el gobierno del territorio y el patronazgo sobre el monasterio de Quejana. En el año 1414, en compensación por desposeer a las religiosas de Quejana del monasterio de Arrigorriaga, concedió los 800 maravedís de moneda vieja que poseía sobre la martiniega y el yantar de la villa de Arceniega. ${ }^{36}$ Este trueque fue una consecuencia directa de los acuerdos alcanzados entre los linajes de Ayala, representado por el que suscribía, y el de Avendaño, encabezado por Martín Ruiz de Avendaño, padre del que iba a ser beneficiario de la iglesia, tras el enfrentamiento que mantuvieron por la anexión de la casa solariega de Orozco, a principios del siglo XV. Tras la muerte de Martín Ruiz, el pacto se selló con su hijo, Juan de Avendaño. Su consecuencia inmediata fue la asignación de Orozco y Llodio para la Casa de Ayala, mientras que Arrigorriaga y Marquina de Zuya quedaron en poder de la Casa de Urquizu, bajo titularidad de los Avendaño. ${ }^{37}$

Con esta donación se completaron las posesiones que el monasterio adquirió en la villa de Arceniega, con la que mantuvo una tensa relación a lo largo de los siglos XV y XVI, que se materializó en el establecimiento de sucesivos procesos judiciales entre las partes. Las diferencias del monasterio de Quejana con el concejo de la villa de Arceniega se centraron en varias materias. Por un lado, en torno al uso y disfrute de ruedas molineras, sobre las que el cenobio ejercía un monopolio. Por otro lado, en torno a las rentas señoriales que los vecinos del lugar estaban obligados a abonar: el yantar, la martiniega y el pedido.

En marzo de 1431, con la autorización de Juan II, Fernán Pérez de Ayala procedió a la donación de 4.000 maravedís anuales situados sobre el pedido viejo de la ciudad de Orduña. ${ }^{38}$ Esta donación se completó con las mandas que incorporó en su último testamento, otorgado en Salinillas

\footnotetext{
35 Ibídem, Apart. A, 9.

36 Ibídem, Apart. A, 15.

37 García Fernández 2007b: 542.

38 AMQ, Apart. B, Leg. 3, 13.
}

de Buradón, el 12 de mayo de $1436 .^{39}$ En él, cuyo principal objetivo radicaba en el cumplimiento de las mandas previamente establecidas, asistimos a la concesión de 20.000 maravedís que habían de invertirse en las exequias, tanto del testador como de su esposa, María Sarmiento, 10.000 maravedís que debían destinarse a ruegos por su alma, y otros 70.000 maravedís de moneda vieja, para la realización de ciertos aniversarios. Asimismo, instituyó una capellanía, para lo que legó 10.000 maravedís anuales que tenía situados sobre las alcabalas de Orduña, completando de este modo una donación de 14.000 maravedís anuales sobre las rentas de esta importante villa comercial.

Además de las dotaciones económicas, este señor se preocupó por otros aspectos, síntoma evidente de la profunda religiosidad que marcó su vida. ${ }^{40}$ Se conservan varios documentos que dan fe de las gracias de orden espiritual que solicitó al papa, concretamente a Martín V, en nombre del monasterio de Quejana. El 23 de diciembre del año $1417,{ }^{41}$ mientras actuó de embajador de Castilla durante el concilio de Costanza, y amparándose en la estrecha relación entre su familia y el cenobio, así como en el esfuerzo que su padre, el Canciller, había dedicado a solucionar el Cisma de Occidente, requirió al pontífice una serie de gracias que se centraron en tres asuntos principales. En primer lugar, la concesión de diez años de indulgencias a favor del monasterio y todos sus integrantes durante determinadas festividades: Virgen María, Santo Domingo, San Agustín, los Apóstoles, etc. Una segunda petición se centró en proveer a las religiosas que integraban la comunidad monástica de ciertas prerrogativas a la hora de escoger un presbítero idóneo, fuese secular o regular, que pudiese celebrar adecuadamente los oficios divinos y conceder la absolución plenaria. ${ }^{42}$ Finalmente, aludiendo a las dificultades económicas que atravesaba el cenobio, solicitó la concesión de cierta capacidad decisoria que permitiera a las religiosas la libre designación de nuevos beneficiados, además de procurar la limitación de su número.

Por último, el monarca Juan II, en mayo del año 1420, informado de las dificultades que padecían las religiosas cuando debían proceder a la recaudación de la renta que, en el año 1399, Pedro López les había concedido sobre el portazgo de Orduña, procedió a intercambiarla por otra de igual valor -3.000 maravedís anuales- sobre las alcabalas del vino de Orduña. El problema derivó de la negativa de los recaudadores de la ciudad a abonar íntegramente la renta debida:

E dizen que los que agora cojen e recabdan el dicho portadgo, que les fazen muchas cabtelas e encobiertas

39 ARChV, Pergaminos, Caja 57/1. Una copia tardía de este manuscrito, efectuada en el año 1463, se encuentra publicada en Enríquez et alii 1994, Tomo I: 29-32.

40 Esta religiosidad también se manifestó en la edificación del hospital de Santa María del Cabello, sito en Vitoria, cuya fundación acordó juntamente con su esposa. Martín Latorre 1996: 21-34.

41 Díaz de Loizaga 1997: 114-117.

42 Alrededor de esta problemática giraron los otros dos documentos en los que se muestra la intervención de Fernán Pérez de Ayala ante la Santa Sede, emitidos el 3 de mayo de 1419 y el 1 de julio de 1428. Ibídem: 121 y 152-153. Por tanto, se trata de un problema recurrente, probablemente relacionado con la solución que Clemente VI, en 1267 , dio al conflicto de la cura monialium, que eximía a los frailes predicadores de la responsabilidad de atender los asuntos espirituales de las monjas dominicas, labor que se asignó a los clérigos seculares. 
deziendo que non monta tanto el dicho portadgo como los dichos tres mill maravedis, e que las cohechan en tal manera que non les pagan los dichos maravedis enteramente, e les fazen dar carta de pago de todos los dichos tres mill maravedis enteramente en caso que los non resçiben. ${ }^{43}$

Así, quedó plenamente configurado el conjunto patrimonial que el monasterio de Quejana poseyó sobre la ciudad de Orduña, integrado por una serie de rentas situadas sobre las alcabalas, los diezmos de la mar y el pedido viejo de este importante enclave comercial, que ascendió a 18.500 maravedís anuales. La transcendencia económica de estos bienes, que se convirtieron en sustento principal del cenobio, debe vincularse con el interés que los señores de Ayala manifestaron a lo largo de toda su historia por integrar bajo su jurisdicción esta ciudad, aspiraciones que nunca llegaron a verse cumplidas. ${ }^{44}$

\subsection{Los últimos Ayala: Pedro López y su hermana Constanza} (1436-1472)

La descendencia directa de Fernán Pérez y su esposa, al menos su primogénito, Pedro López, y su hija menor, Constanza de Ayala, se encargaron de efectuar las donaciones pertinentes a la institución tras el deceso de sus progenitores. Este Pedro López, a pesar de contraer nupcias con tres mujeres diferentes, falleció sin herederos, por lo que prohijó a uno de sus sobrinos, García López de Herrera, ${ }^{45}$ hijo de otra de sus hermanas, María de Ayala, y de su esposo, Pedro García de Herrera, señor de Ampudia y mariscal de Castilla. Por otro lado, la dotación otorgada por Constanza de Ayala en su testamento, caracterizada por la institución de una capellanía perpetua y la concesión de una renta para su financiación, inauguró un ciclo protagonizado por las mujeres del linaje, pues fueron ellas las encargadas de asumir la dotación del cenobio ante el escaso interés mostrado por los señores procedentes de la rama de Ampudia a partir de los años 90 del siglo XV.

La única donación de Pedro López de Ayala se efectuó en octubre del año 1463 y su finalidad fue claramente expiatoria:

Por quanto yo soy en debda e cargo de dar e pagar a vos, las onorables sennoras e devotas religiosas, priora e duennas e conbento del monesterio de Sant Johan de Quexana, que es hedificado en la mi tierra de Ayala, çiertas quantias de maravedis, asy por razon de algunas mandas que al tienpo de su finamiento e postrimera e última voluntad mi sennor padre, Ferrnand Perez de Ayala, que Dios dé santo parayso, vos fizo, commo por cabsa de otras cargas muchas que de vos tengo. ${ }^{46}$

Esta concesión se realizó en un momento muy concreto, cuando este señor se encontraba aquejado por alguna enfermedad, probablemente la que derivó en su deceso, pues a finales de este año tenemos a García López de Ayala asumiendo las funciones del señorío al dictar una sentencia

43 AMQ, Apart. A, 20.

44 Una descripción de las ambiciones del linaje sobre Orduña puede encontrarse en González Cembellín 1990: 68-70.

45 La adopción fue aprobada por Enrique IV el 15 de marzo de 1458. RAH, Col. Salazar y Castro, D-10, fols. 281-285.

46 AMQ, Apart. A, 25 arbitral favorable al cenobio desde el palacio de Quejana. Por tanto, es razonable considerar que estaba poniendo en orden sus asuntos antes de su fallecimiento.

La donación supuso la concesión de los derechos señoriales que el linaje poseía sobre el lugar de Andollu, con la única condición de que su sucesor mantuviese la jurisdicción civil y criminal sobre el territorio, y todo lo a ello perteneciente. Es decir, los pagos derivados del ejercicio de la justicia, unos ingresos muy cotizados. Asimismo, conservó el derecho a percibir las aves, gallinas y capones que los renteros estaban obligados a aportar a su señor. Así, los derechos del monasterio se redujeron al cobro de la infurción del lugar y de los diezmos de su iglesia, por encontrarse ésta bajo su patronazgo.

No obstante, la preocupación del último de los Ayala por el bienestar de las religiosas de Quejana también se dejó sentir en otros ámbitos ajenos a los dotacionales. Las fuentes reflejan su mediación en un intercambio de rentas que el convento formalizó en el año 1457 con Ladrón de Guevara, por el que se permutaron 2.000 maravedís de renta anual que el monasterio poseía sobre Escalante por otra renta de igual valor en Morillas: «por quanto el dicho sennor Pero Lopez de Ayala por vos, el dicho don Ladron de Guevara, e en vuestra voz e en vuestro nonbre, nos las dio e ha dotado e sytuado ". ${ }^{47}$

Su hermana, Constanza de Ayala, también se interesó por las religiosas de Quejana en el momento final de su vida. En su testamento, emitido en noviembre del año 1472, instituyó una capellanía, para la que legó, además de joyas y vestimentas, los 5.000 maravedís de renta anual que tenía situados sobre las alcabalas de la ciudad de Vitoria. Esta donación no fue la primera elección de la testadora, quien en un primer momento otorgó al cenobio su lugar de Tuyo. Sin embargo, la dificultad que hubiese supuesto para la comunidad el acceso a esos bienes determinó la concesión de la renta anual de Vitoria. ${ }^{48}$ Asimismo, una transcripción completa de su testamento y codicilos permite advertir otras disposiciones ordenadas por esta doña: 2.780 maravedís y dos libras de cera, destinados a cubrir los gastos derivados de sus exequias y paliar las desigualdades sociales existentes en la comunidad. ${ }^{49}$

\section{LA LLEgAdA dE LOS HeRRERA A LA TIERRA de AyALA: PUNTO DE} INFLEXIÓN EN LA FORMACIÓN PATRIMONIAL DEL MONASTERIO (1463-1525)

Tras la muerte de Pedro López de Ayala sin descendencia, con la extinción de la rama principal de los Ayala y el ascenso de la rama procedente de Ampudia, encabezada por García López de Ayala, mariscal de Castilla, se advierte una progresiva reducción de la protección hacia el monasterio de Quejana, como demuestran las escasas donaciones que este señor practicó y las malas relaciones que se establecieron entre su hijo, Pedro de Ayala, conde de Salvatierra, y el cenobio ayalés. Ante esta coyuntura, las mujeres del linaje, fundamentalmente la esposa e hijas del mariscal García López, tomaron el relevo y se encargaron

\footnotetext{
47 ARChV, PI. Civiles, Alonso Rodríguez (D), Caja 7,1, fol. 69.

48 AMQ, Apart. B, Leg. 2, 38.

49 La transcripción de este documento se encuentra publicada en Ayerbe Iríbar 1985: 167-183.
} 
de cubrir las necesidades materiales y espirituales de la comunidad, pues impulsaron la introducción de la reforma religiosa desarrollada por el cardenal Cisneros, mediante la que se promovía la reducción a la regular observancia de los monasterios peninsulares. ${ }^{50}$

Ante la nueva situación, las religiosas se vieron en la necesidad de modificar la gestión de ciertas posesiones que se encontraban en pésimas condiciones. Para ello, recurrieron al establecimiento de censos enfitéuticos con carácter vitalicio: Salinas de Añana en $1466,{ }^{51}$ Orduña en $1484^{52}$ y Salinillas de Buradón en $1491 .^{53}$ Los motivos que impulsaron al cenobio a primar este sistema de explotación frente a otros deben vincularse con la baja rentabilidad de las propiedades, el alto coste de su explotación y el fracaso del establecimiento de contratos de arrendamiento previos. Por tanto, su objetivo se centró en mejorar el rendimiento de los bienes, que en ocasiones se encontraban en un estado ruinoso, e incrementar las ganancias del cenobio con su puesta en produccción, además de hacer frente a las deudas que lo acuciaban. El ejemplo más ilustrativo a este respecto se observa en el censo de Salinas, en el que se advierte con nitidez las dificultades económicas que atravesó el monasterio de Quejana desde mediados del siglo XV. Esta circunstancia resultó determinante en la decisión de rehabilitar las ruedas de Salinas, abandonadas medio siglo atrás:

Por quanto el dicho monesterio de Sant Juan e nos en su nonbre al presente estamos grabadas de algunos debdos, nesçesario asy para pagar las dichas debdas commo para çiertos refazimientos de çiertas labores que son nesçesarias, asy en el dicho monesterio commo para refazer e reparar un solar de rueda e heras de sal fazer que el dicho monesterio e nos en su nonbre hemos e tenemos en el balle de Saltrazera (?), que es // en la villa de Salinas de Anana (...), e estando todas destruydas e caydas, en manera que ha más de quarentya e çinquenta annos, por tal manera, que nunca en todo este dicho tienpo obimos nin podimos a[ber] de todo ello nin de cosa alguna renta alguna que [...]ese nin a nos aprobechase.

\subsection{Abandono de la tutela señorial durante el señorío de los Herrera}

La herencia que García López de Ayala recibió fue fortuita, pues él era un tercer hijo. La prematura muerte de su hermano mayor, Pedro López de Herrera, mariscal de Castilla y señor de Ampudia desde el fallecimiento de su padre en el año 1455, le situó al frente de las propiedades familiares y le convirtió en heredero universal de los mayorazgos de Ampudia y de Ayala. Fue precisamente este Pedro López de Herrera quien designó a su hermano en su testamento, otorgado el 13 de abril de 1457: «mando el maiorazgo de Fuentepudia e Villazidalher a Garcia de Ferrera,

50 La bibliografía general sobre la reducción a la observancia, así como la específica dedicada al estudio de su progresiva propagación por la orden de los Predicadores en los reinos castellanos es significativa. Mencionaremos algunas obras de referencia: Cantera Montenegro 2004; García Oro 1971; Graña Cid 2010: 291-306; Heredia 1939; Nieva Ocampo 2006 y Pérez Vidal 2012.

$51 \mathrm{AMQ}$, Apart. 2, Leg. 14, 3.

52 Ibídem, Apart. A, 28.

53 Ibídem, Apart. B, Leg. 2, 41. mi hermano, segun que está vinculado por el mariscal, mi señor y padre». ${ }^{54}$

Apenas ocho días después de la emisión de este testamento, Enrique IV dictó una sentencia de destierro de un importante grupo de Parientes Mayores guipuzcoanos, vizcaínos y alaveses, entre los que se encontraba el entonces señor de Ayala, Pedro López. A diferencia de las penas que tuvieron que afrontar la gran mayoría de ellos, enviados a la frontera andaluza, el monarca fue indulgente con el señor de Ayala, y le permitió retirarse a casa de su hermana, María de Ayala, hasta la primavera del año 1458. Fue entonces cuando Pedro López tomó contacto con su sobrino y le prohijó. ${ }^{55}$

El testamento y codicilos del mariscal Ayala, otorgados a lo largo del mes de octubre del año 1485, durante su convalecencia, recogen tres únicas mandas a favor de Quejana, aunque sólo una de ellas incorporó un elemento renovador: la concesión de los derechos de explotación sobre las ruedas de Mendíjur. Las otras dos establecieron modificaciones en ciertas propiedades ya pertenecientes al cenobio: la devolución del monasterio de Albizulezaga, que por razones no especificadas se integró en la jurisdicción del mariscal, y el intento de permutar los derechos señoriales del cenobio sobre el lugar de Andollu por una renta de idéntico valor en «las mijorias de la dicha tierra de Ayala». ${ }^{56}$

La donación de los derechos de explotación sobre este ingenio cerró el cómputo total de ruedas molineras que poseyó el monasterio de Quejana. La escasa información descriptiva que disponemos, pues fundamentalmente conocemos su existencia por su inclusión en los documentos en que se procedió a su dotación, no nos permiten precisar con exactitud las características técnicas de estos ingenios. Aunque, los textos en los que se aprecia una descripción más detallada de los mismos, y su localización en lugares próximos a cauces fluviales, permiten afirmar que fueron molinos hidráulicos.

El censo se convirtió en el sistema de explotación más habitual de estos ingenios, proporcionando al cenobio unos ingresos estables. Asimismo, la costumbre que obligaba al censatario a ocuparse del mantenimiento de los edificios eximía al cenobio de cualquier inversión en los mismos, garantizando unos ingresos libres de gastos. Sin embargo, las transformaciones que fue sufriendo el sistema de medida del trigo provocaron ciertas variaciones en la renta percibida a lo largo de los años.

Asimismo, resulta indispensable señalar que la relevancia de la posesión de derechos de titularidad sobre ruedas de molino no se centraba exclusivamente en los beneficios de carácter económico que reportaban. Al mismo tiempo, garantizaban una serie de ventajas a sus propietarios, primacías que transcendían el umbral económico y adquirían una significación social: posibilidad de nombrar molinero encargado de la recaudación de la renta, favoreciendo la incorporación de individuos afines; percepción de la renta derivada de su uso por la comunidad, cuyo importe suponía un ingreso estable; y finalmente, el propio aprovechamiento

54 Asimismo, este texto contiene una manda dedicada a Quejana: «10.000 maravedis a Santa Maria del Cabello, que es en Quexana». RAH, Col. Salazar y Castro, D-10, fols. 307-310.

55 García Fernández 2007a: 214-216.

56 AMQ, Apart. B, Leg. 2, 45. 
del molino, de libre uso para su propietario y de uso obligado para los lugareños. Así, la transcendencia de los molinos radicó en su simbolismo, pues fueron una representación del dominio señorial sobre el campesinado, en este caso de un señorío eclesiástico. ${ }^{57}$

A su muerte, su hijo, Pedro de Ayala, conde de Salvatierra, conocido por su participación en el conflicto de las Comunidades, asumió el gobierno del territorio. El periodo de su mandato, que transcurrió entre los años 1485 y 1524, se caracterizó por una fuerte conflictividad entre éste y muchos de los lugares que se encontraban bajo su jurisdicción, que abarcaban diversos términos de los actuales territorios de Álava, Vizcaya y Palencia. ${ }^{58}$ En este contexto, el monasterio de Quejana no constituyó una excepción.

Los primeros síntomas del enfrentamiento judicial que protagonizaron se manifestaron en agosto del año 1498, en una comisión otorgada por los Reyes Católicos a fray Pascual de Ampudia, obispo de Burgos. El texto señala la existencia de una discrepancia en torno al cobro de ciertas rentas, concretamente, los 10.000 maravedís situados sobre el pedido viejo de la ciudad de Orduña, legados por Fernán Pérez de Ayala en su testamento del año 1436, y los diezmos y rentas derivados del patronato sobre las iglesias monasteriales de Albizulezaga, en Orozco, y las de Abecia y Abornícano, en Urcabustaiz. El problema surgió de la usurpación llevada a cabo por el conde de Salvatierra unos meses antes.

A pesar de que desde un principio estas fricciones se encauzaron pacíficamente, se suscitó un temor real entre los miembros de la comunidad monástica ante posibles represalias violentas. La prueba más evidente de este sentimiento, que no era infundado, se reflejó en la emisión de un seguro real, el 3 de agosto de 1498 -tan sólo dos días después de haberse otorgado la carta de comisión al obispo de Burgos-, a solicitud de los miembros de la comunidad, temerosos de posibles agresiones del conde o de sus paniaguados. Este amparo no pareció surtir el efecto deseado y aproximadamente dos meses después de su emisión, el 19 de octubre, se registra la noticia del intento de homicidio de Alonso de Castro, procurador y médico del monasterio, y uno de los individuos que figuraban en el seguro real como víctima probable.

A partir del año 1502, la parte del monasterio de Quejana incorporó una nueva reclamación: la restitución de cierta plata que las monjas habían prestado a Pedro de Ayala con motivo de su partida a la guerra de Granada en el año 1488 , para financiar su campaña y a condición de que la devolviese a su retorno. El incumplimiento de este compromiso determinó este nuevo requerimiento.

Entre los años 1502 y 1512 se produce un vacío documental en torno a esta problemática. Sin embargo, el conflicto se reanudó a partir del año 1512, encauzándose por vía judicial, ${ }^{59}$ de modo que se instruyó un pleito que se pro-

57 Díaz de Durana 1997; Martín Prieto 2006 y Ortuño Molina 2005-2006.

58 Una descripción de los conflictos entablados en el territorio vasco puede encontrarse en García Fernández 2001b: 85-110.

59 Las referencias documentales que nos informan acerca de este litigio son cuantiosas: AGS, RGS, Leg. 149808, 231 -primera comisión real para investigar el conflicto, 1 de agosto de 1498-; Ibídem, Leg. 149808, 160 -seguro real contra posibles abusos del conde, 3 de agosto de 1498-; Ibídem, Leg. 149810, 134 -pesquisa sobre el intento de asesinato de un miembro de la comunidad a manos de un servidor del conde, su confesor, 19 de octubre de 1498-; Ibídem, Leg. 150208, longó hasta el año 1525, con la emisión de una carta ejecutoria favorable a los intereses del monasterio de Quejana. Las sentencias en ella contenidas, en grado de vista y de revista, condenaron al conde a devolver los derechos que usurpó sobre las rentas de Orduña y Albizulezaga, a asumir la compensación por los años que el monasterio dejó de cobrarlas, a reintegrar la plata que tomó prestada y finalmente al pago de las costas del proceso.

\subsection{El protagonismo dotacional de las mujeres del linaje}

Nos encontramos por tanto ante una evidente desafección de la estirpe palentina ante las necesidades del monasterio de Quejana. Sin embargo, fueron las mujeres del linaje las encargadas de asumir el papel dotacional. ${ }^{60}$ En concreto, las hijas -María, Mencía y Ginesa- y esposa -María Sarmiento- del mariscal Ayala.

María de Ayala, hija del mariscal García López de Ayala y de su esposa, María Sarmiento, condesa de Valencia de don Juan por su matrimonio con Enrique de Acuña, otorgó su testamento en julio del año $1496 .{ }^{61}$ El valor total de los bienes que esta mujer legó a diversas instituciones eclesiásticas e individuos, entre los que destacan sus hermanos y criados, ascendió a un total de 4.236.705 maravedís, exceptuando de esta cantidad las joyas y los ropajes que concedió, esencialmente, como elementos decorativos de la capilla que ordenó edificar. De dicha cantidad, 2.705.705 maravedís se otorgaron a instituciones religiosas, y la inmensa mayoría de ese dinero se destinó al monasterio de Quejana, concretamente, 2.306.205 maravedís. Aproximadamente la mitad de la aportación donada a las iglesias -en torno a 1.300.000 maravedís- cumplió una función salvífica, tanto por su alma como por la de su hermano Fernando, difunto. El dinero restante, concedido a otras instituciones eclesiásticas, presentó un carácter más simbólico, en consonancia con la costumbre de la época de patrocinar las obras de las iglesias y de proporcionar limosnas para pobres. ${ }^{62}$

Uno de los aspectos más distintivos de su testamento es la obligación de las religiosas a reducirse a la regular observancia para poder recibir las mandas testamentarias. Este requisito se apreciará con mayor rotundidad en el testamento de su madre, María Sarmiento:

E digo que, por quanto en el testamento que tengo fecho e otrorgado por ante Alonso de Benavente, escrivano de sus Altezas, tengo mandado e dispuesto que

172 -comisión real para investigar el préstamo de cierta plata al conde, 11 de agosto de 1502-; ARChV, PI. Civiles, Masas (F), Caja 3378,1 -pleito, 1512-1524-; AMQ, Apart. B, Leg. 3, 6-carta ejecutoria, 18 de mayo de 1525-.

60 Paz Moro 2014. Este interés de las mujeres por proteger y beneficiar a los monasterios femeninos fue una constante durante la Baja Edad Media. Así se aprecia en el vecino monasterio de Santa Clara de Medina de Pomar, también desde fines del siglo XV, cuando las esposas de los Velasco, bajo cuyo patronazgo se adscribía el cenobio, se preocuparon por el bienestar del centro. Barrón García 2004: 209-212.

61 AMQ, Apart. B, Leg. 1, 5.

62 La concesión de limosnas a pobres y a hospitales, la financiación de las obras de las iglesias, así como la aportación de dotes a huérfanas para que contrajesen nupcias, entre otras obras meritorias, eran elementos imprescindibles en los testamentos de personas de elevada condición social. García Herrero 1984. 
quando la voluntad de nuestro Señor fuere llevarme d'esta vida mi cuerpo sea sepultado en el monesterio de Sant Johan de Quixana, qu'es en tierra de Ayala, segund que más conplidamente se contiene en la clausula del dicho mi testamento, que çerca d'esto dispone, e porque la capilla que la condesa de Valençia doña Maria de Ayala, mi hija, mandó hazer en el dicho monesterio, en que su cuerpo e de don Hernado de Ayala e doña Mençia, mis hijos e sus hermanos, fuesen sepultados, a donde yo ansymismo me mando sepultar, no está fecha nin acabada a cabsa de los pleytos que se tratan con don Pedro de Ayala, conde de Salvatierra, e con el conde de Valençia, sobre la hazyenda e bienes pertenesçientes a la dicha condesa, mi hija, e asymismo, el dicho monesterio no está aun reduzido en ovservançia enteramente como yo lo deseo e querria, hasta que sea conplido lo uno e lo otro, conviene a saber: la dicha capilla e reduzido enteramente en ovservançia el dicho monesterio, no es mi voluntad que mi cuerpo sea llevado a sepultar al dicho monesterio. ${ }^{63}$

Las mandas otorgadas por María Sarmiento, en octubre del año 1516, aunque no alcanzaron la magnitud de las de su hija, también fueron significativas. Concedió 30.000 maravedís para sus exequias, cuatro cargas de trigo, seis cántaras de vino y ocho libras de cera para su añal, además de 6.000 maravedís de renta perpetua para el mantenimiento de las religiosas, que no percibirían hasta que su cuerpo estuviese enterrado en la capilla mandada edificar por su hija. Asimismo, instituyó una capellanía, para lo que asignó una renta anual de 7.000 maravedís y diez fanegas de trigo. Por tanto, la principal consecuencia de la exigencia de reducirse a la observancia y del retraso en la construcción de la capilla fue de índole económica, no sólo porque el cenobio dejó de ingresar y administrar los 30.000 maravedís destinados a cubrir los gastos de enterramiento y sus misas correspondientes, además de los 6.000 de renta perpetua anual, sino porque el traslado del cuerpo, una vez cumplidas estas exigencias, supondría un desembolso que en buena medida provendría de las arcas monásticas.

El testamento otorgado por Mencía de Ayala, en el año $1509,{ }^{64}$ hija también del mariscal García López y de María Sarmiento, nos muestra, al igual que se observa en los casos de su madre y hermana, la predilección de estas mujeres castellanas por el monasterio de Quejana. La cantidad que concedió al cenobio superó el $50 \%$ del total aportado, que ascendió a 913.670 maravedís. Donó 80.000 maravedís para cubrir los gastos derivados de su enterramiento y las misas obligadas -añal, novenario, trentenario, etc.- Asimismo, instauró una capellanía perpetua, para la que asignó una renta anual de 21.000 maravedís y veinte fanegas de trigo. Concedió, además, medio millón de maravedís para que se procediera a la compra de un juro que cumpliera los requisitos contenidos en dicha capellanía. Así, asistimos a la concesión de casi 600.000 maravedís, cantidad ampliamente sobrepasada si tenemos en cuenta la donación de diversas vestimentas y joyas.

En este contexto, disponemos de un testimonio escrito que da fe del modo en que se cubrieron las necesidades derivadas de la capellanía instaurada por esta doña. Su esposo, Antonio de Fonseca, señor de Coca y Alaejos, en el año 1515, concedió a Quejana los 21.000 maravedís de renta anual que disfrutaba sobre la villa de Castro Urdiales:

\footnotetext{
63 AMQ, Apart. B, Leg. 2, 3.

64 ARChV, PI. Civiles, Taboada (F), Caja 710/1.
}

E agora, señores, yo, queriendo conplir e cumpliendo por don Fernando de Fonsequa e don Johan de Fonseca, mis hijos, e de la dicha doña Mençia, mi muger, las dichas capellanias e memorias, usando de las leyes e hordenanças fechas en las Cortes de Toledo el año pasado de mill e quatroçientos e ochenta años, que çerca d'esto hablan, querria // renunçiar e traspasar, e por la presente renunçio e traspaso en el abbadesa e monjas e convento del monasterio de San Johan de Quexana, que es en el valle de Ayala, donde la dicha doña Mençia, mi muger, está enterrada, nueve mill maravidis de juro de los dichos veinte e un mill maravidis, e en los capellanes que fueron nonbrados para servir las dichas capellanias, otros doze mill maravidis de juro de los dichos veinte e un mill maravidis de juro que assi tengo. ${ }^{65}$

El último ejemplo en el que se advierte la voluntad dotacional de las mujeres del linaje es el protagonizado por Ginesa de Ayala, hija del mariscal y de su esposa. La única referencia documental al respecto es la aportada por el Libro de rentas y apeos, en el que se expresa que su dotación alcanzó el "quinto de toda su hazienda para que se comprase çient mill maravedis para una capellania». ${ }^{66} \mathrm{Se}$ trata de una noticia somera que no nos permite concretar con exactitud la magnitud de la misma, pues se desconoce la hacienda que llegó a concentrar esta doña. Además, la reseña histórica del convento, realizada por el padre Lalastra en el siglo XVIII, señala que "esta manda no llegó a tener efecto por motivos o razones que se ofrecieron para ello", no especificados. ${ }^{67}$

\section{Patrimonio final de QueJana EN 1525}

Además de los bienes cuyo sistema de adquisición se ha conservado, las fuentes registran la existencia de otras posesiones, cuya incorporación bien pudo ser anterior a la fundación del cenobio, por ser de posesión inmemorial: el monte de Aztobieta, heredades en Basabe, la iglesia de Derendano, que podría haber sido una donación del fundador, y la rueda de Gujuli. Asimismo, hay otras propiedades cuya existencia se conoce gracias al establecimiento de censos enfitéuticos. Es el caso de las ruedas de Salinas de Añana, las heredades y ruedas de Orduña y las propiedades de Salinillas de Buradón, previamente citadas.

Una mención especial requiere en este punto la relación de bienes procedentes de las dotes y legítimas de las religiosas que ingresaron como novicias en el monasterio, integrados por tierras de labranza dedicadas al cereal en Villalba y San Martín de Losa, viñas en Tertanga y el monte de Leundica, entre otras. Todas las referencias conservadas acerca de esta práctica son de época tardía, a partir de la segunda mitad del siglo XV. La mayoría de datos proceden de los registros contenidos en el Libro de rentas y apeos, por lo que exclusivamente contienen información acerca de la donación y sus protagonistas, eludiendo incluso la especificación de una referencia cronológica precisa.

65 Ídem.

66 Se trata de un libro ordenado por la priora María de San Bartolomé, cuya redacción se inició en el año 1527. En él se incluye una relación de las propiedades que integraron el patrimonio monástico y los modos de adquisición de las mismas, además de algunos rendimientos que producían. AMQ, Apart. A, 1.

67 Ibídem, Apart. 2, Leg. 14, 20. 
A pesar de ello, se pueden distinguir dos tipos de aportaciones. La dote se otorgaba en metálico y generalmente se empleaba en la adquisición de bienes inmuebles sobre los que el monasterio tenía aspiraciones. Existe una única referencia sobre esta práctica: la dote de Sancha Fernández de Murga, monja en Quejana, al menos entre 1484 y 1513, cifrada en 3.000 maravedís, se empleó en la compra del sel de Leundica. ${ }^{68}$ La legítima, por contra, se componía por heredades sobre las que se concedía una renta anual, que era administrada por las nuevas religiosas hasta su defunción. Este fue el mecanismo que ha dejado más testimonios documentales en Quejana. En estos casos, se registran dos sistemas de adquisición: la donación y la compra. El archivo monástico custodia un único documento que da fe de la donación de una legítima: María Ortiz de Uribe, oriunda de Villalba de Losa, en 1504, donó a su hija, Elvira López de Ayala, monja, las heredades que poseía en dicha localidad, valoradas en ocho fanegas de trigo anuales. ${ }^{69}$ La aportación de legítimas mediante compra tiene su referente en Catalina de San Martín, monja, quien a lo largo de los años 1522 y 1523, adquirió varias heredades en el término de San Martín de Losa. $^{70}$ Así, quedaría totalmente configurado el patrimonio final de Quejana para el primer cuarto del siglo Xvı (véase infra Mapa).

\section{MAPA 1 \\ Contiene el conjunto de posesiones del monasterio de Quejana en 1525 según la información proporcionada por el Libro de rentas y apeos guardado en el archivo monástico (AMQ, Apart. A, 1)}

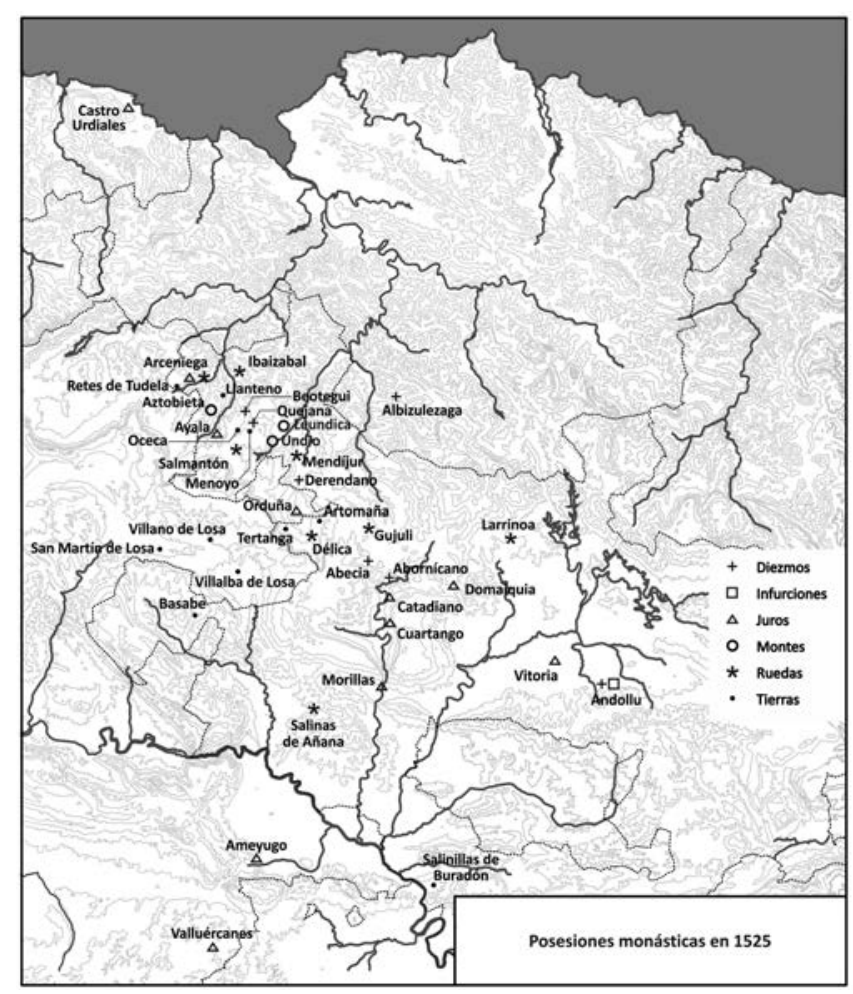

Elaboración: Ismael García.

\footnotetext{
68 Información procede del Libro de rentas y apeos. Ibídem, Apart.

69 Ibídem, Apart. B, Leg. 2, 24.

70 Ibídem, Apart. B, Leg. 5, 53.
} A, 1.

\section{CONCLUSIONES}

La fundación del monasterio de San Juan de Quejana por el linaje de Ayala y los motivos que impulsaron su creación, basados en la justificación dinástica de su acceso al poder, crearon unos fuertes vínculos entre este monasterio y los señores del valle. Esta vinculación fue bidireccional. Los patronos proporcionaban su protección a la comunidad monástica a cambio de los ruegos y oraciones de estas religiosas a favor de su salvación eterna. Así, los Ayala se convirtieron en los principales benefactores del cenobio, monopolizando prácticamente el proceso dotador durante el primer siglo de vida del centro, a excepción de algunas donaciones protagonizadas por los monarcas Juan I y Enrique III, y por Diego Hurtado de Mendoza, con lazos sanguíneos con los Ayala, pues era nieto del fundador.

La extinción de la estirpe ayalesa tras la muerte sin descendencia de Pedro López de Ayala y el acceso al gobierno del territorio por parte de la rama de Ampudia, dio inicio a un periodo de desamparo señorial hacia las religiosas de Quejana, que se materializó en una crisis económica interna. Esta situación abocó a la comunidad a mejorar la gestión de ciertas propiedades que tenían abandonadas, por la necesidad de acceder a esos recursos. El expediente utilizado por las monjas fue el censo, que garantizaba el cobro de una renta y liberaba a los propietarios del mantenimiento de las estructuras. Desde finales del siglo Xv, las mujeres del linaje se encargaron de aliviar las necesidades económicas de las religiosas.

El vínculo establecido entre el patrono y el cenobio no se limitó a la dotación económica de la comunidad y transcendió el ámbito espiritual. Así puede apreciarse en las actuaciones de Fernán Pérez de Ayala, nieto del fundador, que demuestran un gran interés por garantizar la correcta atención espiritual de las religiosas a través de sus requerimientos a la Santa Sede, o en las de María de Ayala y María Sarmiento, hija y esposa del mariscal García López de Ayala respectivamente, con su esfuerzo por introducir la reforma de la regular observancia. Ambas actitudes no pueden desligarse de esa función salvífica asignada a los ruegos formulados por estas religiosas.

En este contexto, fue esta relación la que permitió la adquisición de una gran parte del patrimonio monástico, pues la presencia de compras y permutas entre la documentación monástica es anecdótica. En cualquier caso y como refuerzo de esta idea, cuando se produjeron estas transacciones, derivaron de un interés combinado del cenobio y el linaje bajo cuyo patronazgo se adscribía, como puede apreciarse en la compra de las ruedas de Délica, efectuada por mediación de fray Fernán Pérez de Ayala, en 1382; y la permuta de la martiniega de Escalante por otra de igual valor en Morillas, en 1457, en cuya ejecución colaboró activamente Pedro López de Ayala, el nieto homónimo del Canciller.

Como consecuencia de las dotaciones recibidas, en el patrimonio del monasterio de Quejana cabe distinguir distintos tipos de bienes e ingresos. Destacan, en primer lugar, las rentas: las señoriales, como las infurciones de Andollu; los situados sobre diferentes rentas asignadas a ciudades y villas del entorno monástico; y las eclesiásticas, el diezmo, esencialmente, recaudado y administrado por las parroquias entregadas al cenobio, así como el pie de altar de Quejana. En segundo lugar, la posesión de ruedas de molino en nueve localidades, más por su significación social que económica, 
TABLA 2

Rendimientos anuales generados por el patrimonio de Quejana

\begin{tabular}{|c|c|c|c|c|}
\hline Concepto & Dinero & Trigo & Cebada & Sal \\
\hline Diezmos & $10.000 \mathrm{mrs}$. & 29 fanegas / 2 celemines & 10 fanegas & \\
\hline Infurciones & & 24 y $1 / 4$ fanegas & 2 y $5 / 8$ fanegas & \\
\hline Pie de altar & & 50 fanegas & & \\
\hline Rentas de la tierra & $1.200 \mathrm{mrs}$. & 14 fanegas / 34 celemines & 25 cels. & \\
\hline Rentas reales o señoriales & $55.000 \mathrm{mrs}$. & 100 fanegas & & \\
\hline Ruedas de molinos & & 184 fanegas / 12 celemines & & 6 fanegas / 8 celemines \\
\hline Total (1) & $65.000 \mathrm{mrs}$. & 401 y $1 / 4$ fans. / 48 cels. & 12 y $5 / 8$ fans. / 25 cels. & 6 fans. / 8 cels. \\
\hline
\end{tabular}

Notas a la Tabla 2

(1) Las cifras incorporadas no son absolutas, pues la carencia de libros registro, tanto de gastos como de ingresos, impiden un conocimiento exhaustivo de los rendimientos totales de estas propiedades. Los datos proceden de diversos contratos enfitéuticos y de arrendamiento, de sentencias y del Libro de rentas y apeos.

cuyos beneficios derivaban de la ejecución de censos enfitéuticos sobre ellas. Finalmente, son dignas de mención otras posesiones muebles: dinero en metálico, joyas y vestimentas varias, así como la reliquia de la Virgen del Cabello, de una gran transcendencia cultual en Quejana; o las inmuebles: los montes y las tierras de labranza, dedicadas al cultivo de la vid o el cereal, en gran medida, incorporadas por las dotes y legítimas de las novicias, cuyos rendimientos derivaron también de la imposición de la enfiteusis.

Esta variedad en la tipología de las donaciones contrasta con las recibidas por otros monasterios señoriales del entorno más cercano. Esta realidad se aprecia en primera instancia en el monasterio jerónimo de San Miguel del Monte -o de la Morcuera-, fundado en 1398 bajo iniciativa espiritual de Juan de Guzmán, obispo de Calahorra, y hermano de Leonor de Guzmán, esposa del canciller Ayala. Fue el matrimonio el encargado de la dotación económica del centro, convirtiendo al linaje de Ayala en su patrono. Sus descendientes también mostraron su preocupación por el monasterio; sin embargo, sus aportaciones se centraron principalmente en la financiación de las obras de edificación de sus instalaciones. ${ }^{71}$ Este patrocinio constructivo y artístico también fue predominante en el monasterio clariso de Santa Clara de Medina de Pomar. ${ }^{72}$ Fue fundado a principios del siglo xIV por los Velasco. El cenobio se instituyó como panteón familiar y los diversos miembros del linaje erigieron capillas en las que ordenaron su inhumación. Paralelamente, en este caso también se advierte un interés por garantizar el sustento económico de las religiosas, por lo que recibieron una parte nada desdeñable de las rentas de los diezmos de la mar, adquiridas por el linaje en el año 1469 mediante merced concedida por Enrique IV.

Frente a las características dotacionales de los monasterios mendicantes, resaltan las aportadas a los centros integrados en las órdenes monásticas, esencialmente cistercienses, principalmente villas y aldeas. El linaje de Haro fue un gran patrocinador de esta orden e instituyeron un gran número de casas de este tipo. En Álava fundaron el monasterio de Santa María de Barría al que concedieron

\footnotetext{
71 Vélez 1999.

72 Cadiñanos Bardeci 2004.
}

un reducido señorío jurisdiccional sobre dos aldeas de su entorno: Lacha y Aguirre ${ }^{73}$. Mayor fue su vinculación con los monasterios de Cañas o de Santa María de Herce, a los que otorgaron la posesión de varias villas y numerosos bienes inmuebles ${ }^{74}$.

Una de las características principales del patrimonio de Quejana, esencialmente en lo que a las rentas se refiere, pues es lo que ha quedado constancia en la documentación, es su mutabilidad. Los problemas suscitados por la posesión de las rentas fueron continuos: conflictos relacionados con la negativa de los recaudadores de impuestos a pagar la cantidad íntegra debida -portazgo de Orduña-, o las dificultades de su cobro debidas a la lejanía geográfica de algunas de estas rentas -tal es el caso de Escalante y muy probablemente de Salinas de Añana-, se solucionaron con su intercambio por otras de igual valor y de más fácil acceso.

Finalmente, los situados sobre diversas rentas de la ciudad de Orduña -diezmos de la mar, alcabalas y pedido viejo-, se convirtieron, al menos a lo largo del siglo xV y primera década del XVI, en el sustento principal de la economía monástica. Esta primacía no debe vincularse exclusivamente a la cifra percibida, que fue significativa, sino a que su ingreso estaba plenamente garantizado y no dependía de factores externos para su recaudación y posterior recepción, a diferencia de otras rentas derivadas de la explotación de la tierra. A partir del siglo XVI, las generosas donaciones proporcionadas por las mujeres del linaje, y las rentas que éstas concedieron -concretamente los 21.000 maravedís sobre las alcabalas de Castro Urdiales-, complementaron la economía monástica y se convirtieron en las fuentes de mayores ingresos.

\section{FUENTES Y EDICIONES DOCUMENTALES}

AHN. Archivo Histórico Nacional. Sección Clero. AMQ. Archivo del Monasterio de Quejana. Apartados, A, B y 2. ARChV. Archivo de la Real Chancillería de Valladolid. Pergaminos y Pleitos Civiles.

\footnotetext{
73 Paz Moro 2013: 33-39.

74 Pérez Carazo 2008: 71-115.
} 
Ayerbe Iríbar, M. R. 1985. Historia del Condado de Oñate y Señorío de los Guevara (siglos XI-XVI). Aportación al estudio del régimen señorial de Castilla. II Documentos. San Sebastián: Diputación Foral de Guipúzcoa.

Contreras y López de Ayala, J. (Marqués de Lozoya). 1972. Introducción a la biografía del Canciller Ayala. Bilbao: Junta de Cultura de Vizcaya.

Díaz de Loizaga, S. 1997. Documentación medieval de la diócesis de Vitoria en el Archivo Vaticano (siglos XIV y XV). Zaragoza.

Enríquez, J.; Hidalgo de Cisneros, C.; Lorente, A. y Martínez, A. 1994. Colección documental del Archivo municipal de Orduña (1271 1510). San Sebastián: Eusko Ikaskuntza.

López Yepes, J. 1974. «Documentos sobre el Canciller Pero López de Ayala (1332-1407)». Boletín de la Institución Sancho el Sabio, 28: 101-169.

Martínez Vázquez, F. 1975. «Reseña Histórica y catálogo monumenta del Monasterio de Quejana (1374-1974): VI Centenario». Boletín de la Institución Sancho el Sabio 19: 68-169.

Ojánguren Iralakoa, P. M. 1999. Orozko en la Baja Edad Media. Bilbao: Estudios Gráficos Zure.

RAH. Real Academia de la Historia. Colección Salazar y Castro.

\section{BiBLIOGRAFÍA}

Barrón García, A. A. 2004. «Patrimonio artístico y monumental: e legado de Juan Fernández de Velasco y familiares», en El monasterio de Santa Clara de Medina de Pomar. "Fundación y patronazgo de la Casa de Velasco": 207-276. Medina de Pomar (Burgos): Asociación de Amigos de Santa Clara.

Beceiro Pita, I. 2014. «La nobleza y las órdenes mendicantes en Castilla (1350-1530)», en I. Beceiro Pita (dir.), Poder, piedad y devoción. Castilla y su entorno. Siglos XII-XV: 319-358. Madrid: Sílex.

Cadiñanos Bardeci, I. 2004. «Obras, sepulcros y legado artístico de los Velasco a través de sus testamentos», en El monasterio de Santa Clara de Medina de Pomar. "Fundación y patronazgo de la Casa de Velasco": 177-206. Medina de Pomar (Burgos): Asociación de Amigos de Santa Clara.

Cantera Montenegro, M. 2004. «Las órdenes religiosas». Medievalismo 13-14: 113-126.

Dacosta, A. 1999. «Patronos y linajes en el señorío de Bizkaia. Materiales para una cartografía del poder en la Baja Edad Media». Vasconia. Cuadernos de Historia-Geografía 29: 21-46.

Dacosta, A. 2001. "Apuntes acerca de la dimensión castellana de los Ayala durante la Baja Edad Media», en E. García Fernández (coord.), La tierra de Ayala. Actas de las Jornadas de Estudios Históricos en conmemoración del 600 Aniversario de la construcción de la Torre de Quejana: 101-115. Vitoria-Gasteiz: Diputación Foral de Álava.

Dacosta, A. 2007. El "Libro del linaje de los señores de Ayala" y otros textos genealógicos. Materiales para el estudio de la conciencia del linaje en la Baja Edad Media. Bilbao: Servicio Editorial de la Universidad del País Vasco.

Díaz de Durana, J. R. 1997. "Las bases materiales del poder de los Parientes Mayores guipuzcoanos: los molinos. Formas de apropiación y explotación, rentas y enfrentamientos en torno a la titularidad y derechos de uso (ss. XIV a XVI)». Studia Historica. Historia Medieval 15: 41-68.

Díaz de Durana, J. R. 2001. «Para una historia del monte y del bosque en la Guipúzcoa bajomedieval: los seles. Titularidad, formas de cesión y de explotación». Anuario de Estudios Medievales 31/1: 49-73.

García Fernández, E. 1996. «Dominicos y franciscanos en el País Vasco (siglos XIII-XV)», en J. I. de la Iglesia Duarte, J. García Turza y J. Á. García de Cortázar (coords.), Actas de la VI Semana de Estudios Medievales (Nájera, 31 de julio al 4 de agosto de 1995): 213-234. Nájera: Instituto de Estudios Riojanos.

García Fernández, E. 2001a. «Religiosidad, sociedad y poder político en la Edad Media en torno a Quejana, solar de los Ayala», en E.
García Fernández (coord.), La tierra de Ayala. Actas de las Jornadas de Estudios Históricos en conmemoraicón del 600 Aniversario de la construcción de la Torre de Quejana: 57-80. Vitoria-Gasteiz: Diputación Foral de Álava.

García Fernández, E. 2001b. «Resistencia antiseñorial en el País Vasco: las relaciones entre los Ayala y sus vasallos en la Edad Media», en M. R. Porres Marijuán, (ed.), Poder, resistencia y conflicto en las Provincias Vascas (siglos XV-XVIII): 85-110. Bilbao: Servicio de Publicaciones de la Universidad del País Vasco.

García Fernández, E. 2007a. «El linaje del Canciller don Pero López de Ayala», en F. López López de Ullíbarri (dir.), El linaje del Canciller Ayala: 80-291. Vitoria-Gasteiz: Diputación Foral de Álava.

García Fernández, E. 2007b. «El linaje Avendaño: causas y consecuencias de su ascenso social en la Baja Edad Media». Anuario de Estudios Medievales 37/2: 527-561

García Fernández, E. y Verástegui Cobián, F. 2008. El linaje de la Casa de Murga en la Historia de Álava (siglos XIV-XVI). Vitoria-Gasteiz: Diputación Foral de Álava.

García Herrero, M. C. 1984. "La muerte y el cuidado del alma en los testamentos zaragozanos de la primera mitad del siglo XV». Aragón en la Edad Media 6: 209-245.

García Oro, J. 1971. Cisneros y la reforma del clero español en tiempo de los Reyes Católicos. Madrid: CSIC.

García-Serrano Nebras, F. 2014. «Del convento al palacio: los frailes y las oligarquías castellanas (siglos XIII-XIV)», en I. Beceiro Pita (dir.), Poder, piedad y devoción. Castilla y su entorno. Siglos XII-XV: 77-102. Madrid: Sílex.

González Cembellín, J. M. 1990. «Orduña en la Edad Media: del concejo abierto al concejo cerrado», en Primeras Jornadas de Historia Local. Poder local: 59-75. Donostia-San Sebastián: Eusko Ikaskuntza.

Graña Cid, M. M. 2010. Religiosas y ciudades. La espiritualidad femenina en la construcción sociopolítica urbana bajomedieval (Córdoba, siglos XIII-XVI). Córdoba: Asociación Hispánica de Estudios Franciscanos.

Heredia, B. de. 1939. Historia de la reforma de la provincia de España (1450-1550). Roma: Institutum Historicum FF. Praedicatorum.

Lahoz, M. L. 1993a. «Reflexiones acerca del proyecto funerario de Don Fernán Pérez de Ayala en Quejana». Boletín de la Real Sociedad Bascongada de Amigos del País 49/2: 469-492.

Lahoz, M. L. 1993b. «La capilla funeraria del canciller Ayala. Sus relaciones con Italia». Boletín del Museo e Instituto Camón Aznar 53: 71-112.

Lahoz, M. L. 1995. «En torno al panteón de don Fernán Pérez de Ayala». Sancho el Sabio. Revista de cultura e investigación vasca 5: 285-297.

Lahoz, M. L. 1997. "Promoción y mecenazgo nobiliar en el gótico en Álava». Sancho el Sabio. Revista de cultura e investigación vasca 7: 293-311.

Lahoz, M. L. 2001. "Quejana: promoción y mecenazgo de los Ayala», en E. García Fernández (coord.), La tierra de Ayala. Actas de las Jornadas de Estudios Históricos en conmemoración del 600 Aniversario de la construcción de la Torre de Quejana: 191-217. Vitoria-Gasteiz: Diputación Foral de Álava.

Lahoz, M. L. 2007. «De palacios y panteones. El conjunto monumental de Quejana: imagen visual de los Ayala», en Exposición Canciller Ayala: del 18 de abril al 26 de julio de 2007: 44-97. Vitoria-Gasteiz: Diputación Foral de Álava.

Martín Latorre, P. 1996. Hospitales, peregrinos y... otras cosas. VitoriaGasteiz: Ayuntamiento de Vitoria-Gasteiz.

Martín Prieto, P. 2006. «Aportación al estudio del molino hidráulico en la Castilla medieval: los molinos del monasterio de Santa Clara de Alcocer». Hispania. Revista Española de Historia 66/224: 833-850.

Melero Moneo, M. L. 2000. «Retablo y frontal del convento de San Juan de Quejana de Álava (1396)». Locus amoenus 5: 33-51.

Munita Loinaz, J. A. et alii 2014, "En tiempo de ruidos e bandos". Nuevos textos para el estudio de los linajes vizcaínos: los Barroeta de la merindad de Marquina (1355-1547). Bilbao: Servicio Editorial de la Universidad del País Vasco. 
Nieva Ocampo, G. 2006. "La creación de la observancia regular en el convento de San Esteban de Salamanca durante el reinado de los Reyes Católicos». Cuadernos de Historia de España 80: 91-126.

Ortuño Molina, J. 2005-2006. «Recursos hídricos y política de aguas en el sureste de la Península Ibérica durante la Baja Edad Media». Miscelánea Medieval Murciana 19-20: 123-151.

Paz Moro, A. 2013. El monasterio de Barría. Historia y documentos (12321524). Bilbao: Servicio Editorial de la Universidad del País Vasco.

Paz Moro, A. 2014. «Promoción y patronazgo religioso femenino: e linaje de Ayala y su monasterio familiar de San Juan de Quejana (Ayala, Álava)», en J. Brufal Sucarrat (coord.), Nuevas aportaciones de jóvenes medievalistas. Lleida 2014: 29-42. Murcia: Universidad de Lérida / Centro de Estudios Medievales de la Universidad de Murcia / Sociedad Española de Estudios Medievales.

Pérez Carazo, P. 2008. Santa María de Herce y su abadengo en la Edad Media. Logroño: Instituto de Estudios Riojanos / Universidad de La Rioja.

Pérez Vidal, M. 2012. «Observancia y rigorismo. Consecuencias de la reforma de la orden de Predicadores y de algunos movimientos rigoristas en la liturgia y arquitectura de los monasterios de dominicas de la Provincia de España», en N. Fernández Rodríguez y M. Fernández Ferreiro (coords.), Literatura medieval y renacentista en España: líneas y pautas: 801-812. Salamanca: Semyr. Seminario de Estudios Medievales y Renacentistas.

Pérez Vidal, M. 2013. «Uniformitas versus diversitas en los monasterios femeninos de la Orden de Predicadores en Castilla (siglos XIIIxv)». Territorio, sociedad y poder 8: 133-152.

Portilla, M. 1961. El relicario de la Virgen del Cabello en el Monasterio de Quejana. Vitoria-Gasteiz: Diputación Foral de Álava.

Portilla, M. 1983. Quejana, solar de los Ayala. Vitoria-Gasteiz: Diputación Foral de Álava.

Uriarte Lebario, L. M. 1974. El Fuero de Ayala. Introducción: Antonio María de Oriol y Urquijo, Vitoria-Gasteiz: Diputación Foral de Álava.

Vélez, J. 1999. San Miguel del Monte: arte, patronos y arquitectos en un monasterio jerónimo. Miranda de Ebro (Burgos): Instituto Municipal de Historia. 